\title{
Educação musical e diversidade: aproximações
}

\begin{abstract}
Cristiane Almeida*
\section{Resumo}

Este artigo apresenta um panorama da literatura produzida sobre diversidade e educação musical e sua relação com a legislação educacional brasileira referente à Educação Básica, objetivo geral deste trabalho. Para isso, realizei uma pesquisa bibliográfica que incluiu os documentos educacionais oficiais e a produção teórica de educadores musicais, nacionais e internacionais. Dentre os resultados encontrados, aponto os diferentes conceitos que fazem parte da construção teórica do conceito de diversidade na educação musical, tais como educação musical multicultural, competência intercultural, entre outros. Além disso, apresento outras categorias que foram incluídas mais recentemente, como gênero, raça, orientação sexual, e que se assemelham àquelas explicitadas nos documentos referentes à Educação Básica. A concepção de educação musical multicultural, que priorizava o repertório, foi ampliada, incluindo, assim, outras categorias, tornando-a mais inclusiva. Essa mudança não deve ser só retórica ou com o fim de atender à legislação, mas refletir a postura política dos educadores musicais.
\end{abstract}

Palavras-chave: diversidade, educação musical, legislação educacional brasileira.

\section{Music education and diversity: approaches}

\begin{abstract}
The aim of this paper is to provide a broad overview of the literature on diversity and music education and its relationship with the primary and secondary education Brazilian legislation. Thus I performed a research that included official educational documents and academic production of national and international music educators. Among the findings, I point out the different concepts that take part of the theoretical construct of the concept of diversity in music education, such as multicultural music education, intercultural competence, and others. In addition, I describe other categories that were included more recently, such as gender, race, sexual orientation, and which resemble those made explicit in the documents relating to primary and secondary education. The concept of multicultural music education, which emphasized the repertoire, has been expanded, thus including other categories, making it more inclusive. This change can not be just rhetoric or made with the purpose of complying with the legislation, but, rather, it should reflect the political stance of music educators.
\end{abstract}

Keywords: diversity, music education, brazilian educational legislation.

\footnotetext{
* Professora Doutora da Universidade Federal de Pernambuco. Recife, Pernambuco, Brasil.
} 


\section{Cristiane Almeida}

\section{Introdução}

Dentre as possibilidades de se pensar sobre a educação musical na Educação Básica, está aquela em que confrontamos a legislação educacional e a produção teórica da área em uma tentativa de iniciar a configuração do "estado da arte" ou "estado do conhecimento" que, segundo Ferreira (2002, p. 258), são pesquisas "reconhecidas por realizarem uma metodologia de caráter inventariante e descritivo da produção acadêmica e científica sobre os temas que busca investigar". Foi nesse sentido que escolhi tratar, neste artigo, do termo diversidade, presente em vários documentos oficiais que tratam da Educação Básica, tanto no âmbito das diretrizes curriculares quanto no âmbito da formação de professores, e sua inserção na literatura produzida por educadores musicais.

Dessa forma, este texto será apresentado em três partes. Na primeira parte aponto alguns documentos que fazem referência ao termo diversidade e seus diferentes significados. Na segunda parte farei uma exposição sobre as primeiras aproximações da educação musical com o termo diversidade, especialmente a partir do séc. XX. Na terceira, apresento as produções mais recentes sobre o tema, concluindo, assim, o mapeamento inicial sobre diversidade e educação musical.

\section{Diversidade e Educação Básica: o que diz a legislação}

No Brasil, a legislação educacional menciona conceitos comumente associados ao termo diversidade já no artigo $3^{\circ}$ da Lei de Diretrizes e Bases da Educação Nacional - LDBEN, Lei n. 9394, (BRASIL, 1996). O "pluralismo de ideias e de concepções pedagógicas" e o "respeito à liberdade e apreço à tolerância" integram os princípios-base do ensino, nas alíneas III e IV, da referida lei. Em relação aos currículos para o Ensino Fundamental e Médio, está prevista, no artigo 26, a inclusão de uma "parte diversificada", que atenda às características regionais e locais. No que diz respeito às diferenças étnicas, a lei prevê a "oferta de educação bilíngue e intercultural aos povos indígenas" (artigo 78) e o ensino de história do Brasil que considere as "matrizes indígenas, africanas e europeias" (parágrafo $4^{\circ}$ do artigo 26 ).

Ainda na década de 1990, o Ministério da Educação disponibilizou para todos os professores do Ensino Fundamental os Parâmetros Curriculares Nacionais (PCN) que apresentavam, além dos conteúdos específicos de cada área tratada nesse nível de ensino, uma nova possibilidade de se trabalhar conhecimentos vinculados à pluralidade cultural, além de ética, meio ambiente, saúde, orientação sexual, trabalho e consumo, e que foram denominados de temas transversais.

Embora a pluralidade cultural seja comum a todas as disciplinas curriculares do Ensino Fundamental, no volume que trata sobre o ensino de Arte é salientada a importância dessa área em trabalhar com essa temática, pois "na 
sala de aula inter-relacionam-se indivíduos de diferentes culturas que podem ser identificados pela etnia, gênero, idade, locação geográfica, classe social, ocupação, educação, religião" (BRASIL, 1998, p. 41).

Essas possíveis formas de se tratar a diversidade são retomadas, em 2001, no parecer do Conselho Nacional de Educação (CNE) sobre as Diretrizes Curriculares Nacionais para a Formação de Professores para a Educação Básica. Ao tratar a reforma curricular como um instrumento para transformar em realidade as propostas da Educação Básica, o documento afirma: "Reforça-se, também, a concepção de professor como profissional do ensino que tem como principal tarefa cuidar da aprendizagem dos alunos, respeitada a sua diversidade pessoal, social e cultural" (BRASIL, 2001, p. 9). Além do Parecer, a Resolução do CNE/CP n. 1/2002, que institui essas Diretrizes, aponta "o acolhimento e o trato da diversidade" (BRASIL, 2002, p. 1) como um dos itens referentes à formação docente, na alínea II do artigo $2^{\circ}$. Esse acolhimento e trato são dirigidos também aos portadores de necessidades especiais. A Política Nacional de Educação Especial na perspectiva da Educação Inclusiva de 2008 tem como um de seus objetivos a "garantia do acesso à escolarização na sala de aula comum do ensino regular" (Ice.mec.gov.br).

Outro aspecto abordado na legislação diz respeito às relações étnicoraciais. A Lei n. 10.639/03 - MEC, que altera a Lei n. 9.394/96 de Diretrizes e Bases da Educação Nacional e torna obrigatório o ensino de História e Cultura Afro-Brasileira e Africana na Educação Básica, veio como resposta "a demanda da população afrodescendente, no sentido de políticas de ações afirmativas" (BRASIL, 2004, p. 9) e atendimento ao "determinado pelo Programa Nacional de Direitos Humanos, [...] a Convenção da Unesco de 1960 [...] e a Conferência Mundial de Combate ao Racismo, Discriminação Racial, Xenofobia e Discriminações correlatas de 2001" (p. 11).

Outro viés encontrado nas políticas públicas sobre diversidade diz respeito aos indígenas. As ações direcionadas a esses povos resultaram de um processo que vem, mais acentuadamente, desde os anos de 1970, com o surgimento de organizações civis, "compostas por pesquisadores não-índios principalmente, antropólogos e linguistas - indigenistas e missionários leigos" (HENRIQUES et al., 2007 p. 15). Ainda de acordo com Henriques et al. (2007, p. 16), "as políticas públicas relativas à Educação Escolar Indígena pós-Constituição de 1988" passam a ser atribuição do Ministério da Educação, a partir do Decreto Presidencial n. 26/1991.

\section{Diversidade e educação musical: primeiras aproximações}

O termo diversidade se apresenta na educação musical especialmente em seu viés cultural. Para Campbell e Schippers (2005), a diversidade cultural, presente em muitas práticas educativo-musicais, ainda é reflexo da educação musical desenvolvida no século XIX ou de estudos da etnomusicologia, rea- 


\section{Cristiane Almeida}

lizados nos anos de 1960. Reflete, também, os vários momentos em que se buscou construir o que se denominou de educação musical multicultural.

A junção do termo multicultural à educação musical sugere que a discussão sobre a diversidade na educação musical também incorporou o multiculturalismo. Mas a utilização da palavra multicultural, por si só, talvez não "assegur[e] a presença do multiculturalismo como eixo configurador das reflexões empreendidas" (CANEN; ARBACHE; FRANCO, 2001, p. 163). Ou melhor, é possível identificar "multiculturalismos" nessas reflexões. A educação musical multicultural não é um conceito recente e, por isso, vários são os autores que o utilizam, entre eles, Elliott (1989), Jordan (1992), Volk (1993), Anderson e Campbell (1996), Burton (1997), Ikehara (2001) e Abril (2006).

Com o objetivo de situar o termo em uma linha temporal, Volk (1993) aponta Egon Kraus como o primeiro educador musical a abordar esse tema em uma conferência da Internacional Society for Music Education (ISME), que foi publicada no Music Educators Journal (MEJ), em janeiro de 1967. Em seu discurso, Kraus (apud VOLK, 1993, p. 138) desafiou a ISME e os educadores musicais a resolverem os oito problemas por ele apontados, que envolviam, entre outros pontos, a inclusão de culturas musicais estrangeiras em todos os níveis de educação, a renovação das metodologias de percepção auditiva, rítmica e de teoria musical que incluísse a música de outras culturas, a revisão dos livros-texto e outros materiais didáticos considerando o preconceito e as atitudes racistas e nacionalistas neles apresentados e a preparação de materiais didáticos que incluíssem músicas de outras culturas, utilizando, de preferência, gravações autênticas dessas músicas.

Nesse artigo, a autora apresenta a história e o desenvolvimento da educação musical multicultural como evidenciado no Music Educators Journal (MEJ), de 1967 a 1992. Os três conceitos formadores desse tema são assim expostos:

\footnotetext{
"cultura" é definida como formas aprendidas do pensamento e do conhecimento que habilitam um indivíduo a sobreviver em sociedade. Se "educação musical" é a transmissão dessa parte da cultura que se expressa através da música, "educação musical multicultural" habilita alguém para atuar efetivamente em múltiplas culturas musicais. (VOLK, 1993, p. 139)
}

A ordem cronológica proposta no texto mostra as ações documentadas naquele periódico a partir de 1967, muito embora na introdução a autora lembre que, em 1919, o Music Supervisors Journal, predecessor do MEJ, publicou um artigo de Work intitulado "O desenvolvimento da música negra: da Folk Song às canções e corais 'artísticos'” (VOLK, 1993, p. 140). 
A partir dos anos de 1980, os artigos apontam a necessidade de os cursos de formação de professores apresentarem uma perspectiva multicultural. Em defesa disso, Curtis (apud VOLK, 1993, p. 145) afirma que os

educadores não podem ensinar o que eles próprios não entendem. As escolas de educação superior precisam tornar a educação musical multicultural uma parte do treinamento dos professores a fim de prepará-los para a negociação entre a experiência estética negra com as outras experiências culturais.

Fica evidente, no título do artigo e na citação acima, a ligação com as questões de raça, tema inicial do multiculturalismo. No entanto, as definições posteriores se distanciam desse tema, como sugere a afirmação de Anderson e Campbell:

educação musical multicultural reflete a diversidade cultural do mundo em geral, e dos Estados Unidos, em particular, promovendo um currículo de música que inclua canções, peças corais, seleções instrumentais e a escuta de experiências representativas de uma ampla série de culturas étnicas. (ANDERSON; CAMPBELL, 1996, p. 1)

Como justificativa para essa abordagem multicultural na sociedade americana, os autores apresentam os percentuais de imigrantes que compõem a população dos Estados Unidos. No entanto, não se prendem ao conceito de "melting pot" que estaria em declínio, mas ao de "um país composto de um mosaico de várias comunidades étnicas que contribuem para a cultura nacional mesmo mantendo distintas identidades" (ANDERSON; CAMPBELL, 1996, p. 2). Eles apresentam outras organizações, entre elas a Society for Ethnomusicology, a National Association of Schools of Music e a International Society for Music Education (ISME), como defensoras do estudo de músicas do mundo em todos os níveis de ensino. Essa abordagem é ancorada na literatura da etnomusicologia e o diálogo entre essas duas subáreas da música é proposto como forma de entender a diversidade (ver LUCAS, 1995; TRAVASSOS, 2001).

Dentre as associações citadas, a ISME disponibiliza, em seus valores, algumas recomendações nesse sentido. Para essa organização, "o ensino de música inclui o estudo de qualquer tipo de música, repertórios e instrumentos, e precisa tomar como ponto de partida a existência de um mundo de músicas que merecem ser compreendidas e estudadas" (OLIVEIRA, 2007, p. 59). Além disso, "deve propiciar exposição à música local, música arte do ocidente, música estrangeira como parte do currículo formal de todas as nações; atenção especial deve ser dada às músicas de grupos étnicos e sociais que compõem a população nacional" (OLIVEIRA, 2007, p. 59). 


\section{Cristiane Almeida}

No entanto, Emmanuel (2005) critica a posição da educação musical em priorizar esses aspectos mencionados, ao afirmar que

enquanto o campo de formação de professores tem dado atenção ao ensino de estudantes de formação cultural diversas, o campo da educação musical tem focalizado mais o repertório multicultural do que os processos de ensino e os estudantes culturalmente diversos. (EMMANUEL, 2005, p. 59)

Alguns autores trazem essas diferenças de "gênero, etnicidade, classe social, idade, ou qualquer outra circunstância social" para a discussão sobre o currículo em ação, lembrando que, ao não considerá-las, "tanto o aprendizado como a avaliação acadêmica vão variar, podendo tornar-se não diferenças, mas discriminações" (LOURO; ARÓSTEGUI, 2003, p. 50). Por não ser possível justificálas genética ou naturalmente,

essas desigualdades são necessariamente culturais. [Dessa forma], o sistema educacional só tem duas saídas: 1) negar essas diferenças, e portanto reproduzi-las de forma inconsciente, ou 2) transformar essas diferenças, tornando-se a escola um agente social de mudança. (LOURO; ARÓSTEGUI, 2003, p. 50)

Mesmo assim, a proposição apontada por esses autores retorna ao repertório: "parece ser importante um currículo multicultural no qual a música clássica perca seu caráter hierárquico, e outros estilos musicais pertencentes a grupos invisíveis à academia possam ser incluídos" (LOURO; ARÓSTEGUI, 2003, p. 51).

Emmanuel (2005) aponta, entre as opções para alterar essa tendência da educação musical, a necessidade de se fazer mais investigações sobre os processos de ensino, sem priorizar os conteúdos, e sugere os cursos de formação de professores como foco inicial para esses estudos. Ela alerta, ainda, para as diferenças culturais cada vez mais acentuadas entre professores e futuros professores - monoculturais - e estudantes. Como possibilidade de intervenção, a autora sugere que esses cursos incluam "experiências interculturais significativas" (EMMANUEL, 2005, p. 49). Nessa perspectiva, Emmanuel desenvolveu uma pesquisa com estagiários de música em comunidades culturalmente diversas com o objetivo de identificar os efeitos da imersão nessas comunidades sobre as crenças e atitudes desses professores em formação. Para discutir seu objeto de pesquisa, a autora utilizou o conceito de

competência intercultural, que está baseado sobre a premissa de que, para ser mais eficaz com os estudantes de diversas origens, os estagiários precisam confrontar e examinar suas crenças pessoais em relação aos estudantes tipicamente identificados como "o ou- 
tro", e também para entender como eles se localizam em suas próprias culturas. (EMMANUEL, 2005, p. 50)

Dessa forma, "a música na sala de aula torna-se muito mais que um lugar onde se faz música multicultural. Torna-se um lugar de autodescoberta, aceitação, reflexão, imaginação e, finalmente, de mudança social" (EMMANUEL, 2005, p. 50).

\section{Diversidade e educação musical: outras contribuições}

Além da competência intercultural na educação musical (EMMANUEL, 2005), outros termos foram sendo acrescentados e indicam outras perspectivas teóricas no estudo da diversidade: educação musical em uma sociedade pluralista (SWANWICK, 1988), educação musical em e para uma sociedade multicultural (KWAMI, 1996), educação musical a partir de uma perspectiva multicultural (GIRALDEZ, 1997), educação musical no contexto da diversidade, pluralidade e mudança (BOWMAN, 2003), pensamento crítico na educação musical (GREEN, 2003), educação musical intercultural (O'FLYNN, 2005), pedagogia crítica para a educação musical (COLWELL, 2005; ABRAHAMS, 2005).

Para Schippers (2005), esses termos são usados com frequência mas deveriam ser melhor definidos. Para o autor, a diversidade cultural pode ser pensada a partir das seguintes abordagens:

Monoculturais, na qual a cultura dominante é a única referência; abordagens multiculturais, em que a pluralidade é reconhecida mas nenhum contato ou troca é estimulado; abordagens interculturais, que se caracterizam pelo contato livre entre culturas e algum esforço em direção a um entendimento mútuo; e abordagens transculturais, que representam uma mudança profunda de idéias e valores. (SCHIPPERS, 2005, p. 29, grifo do autor)

No Brasil, os autores que têm discutido sobre diversidade e educação musical têm seguido perspectivas diferentes. Lazzarin (2006), em sua reflexão sobre a Nova Filosofia da Educação Musical (NFEM) e as influências que esta recebeu do multiculturalismo, lembra que este 'termo 'multiculturalismo', de uma maneira geral, vem sendo usado para definir uma visão de mundo que respeita a diversidade de modos de vida de cada sociedade, suas características próprias, seus valores éticos e sua identidade cultural" (LAZZARIN, 2006, p. 125). Em decorrência disso, a influência vai ser explicitada, especialmente, na visão multidimensional da NFEM, "que comporta uma tríplice compreensão do termo "música": uma atividade humana universal, uma atividade humana com manifestações contextualizadas e a cristalização dessa atividade na forma de obras musicais" (LAZZARIN, 2006, p. 125). 


\title{
Cristiane Almeida
}

Ao elaborar essa reflexão, o autor faz, também, uma aproximação com a arte-educação, quando afirma que

A visão multicultural em arte-educação assume ser necessário considerar a maneira como diferentes grupos culturais entendem a arte e a incluem dentro de seus contextos. Questões relativas a etnocentrismo, preconceitos ou racismo devem ser incluídas nessa discussão multicultural, tentando sempre questionar a cultura manifesta e todo tipo de opressão. Somente uma educação que fortalece a diversidade cultural pode ser entendida como democrática. (LAZZARIN, 2006, p. 129)

Para o autor, a NFEM compartilha as proposições multiculturais da arte-educação, quando "afirma que é necessário que todo estudante mova-se para fora de seu contexto musical, em direção aos significados musicais que os contextos não familiares podem proporcionar" (LAZZARIN, 2006, p. 130).

Em texto mais recente, Lazzarin (2008) traz outros elementos a essa reflexão. Entre eles, "discutir alternativas para questões próprias da educação musical, na medida em que ela se insere no movimento geral da cultura contemporânea" (LAZZARIN, 2008, p. 121), a partir de "algumas contribuições do campo dos Estudos Culturais contemporâneos feitas às questões sobre cultura $e$ identidade" (2008, p.121). Um dos pontos salientados, no texto em pauta, diz respeito à

educação musical, como área de produção e de transmissão do conhecimento, [que] em alguns momentos, parece desconsiderar que está inserida em um movimento da cultura que é maior que o simples ensino de música. Em outras palavras, parece ocorrer uma despolitização, no sentido específico das relações entre saber e poder. (LAZZARIN, 2008, p. 124)

Tal despolitização é discutida por Luedy (2006), numa perspectiva crítica, ao tratar da diversidade cultural dos alunos. É seu objetivo

\begin{abstract}
chamar a atenção para o fato de que a educação musical, ao se insular num campo discursivo supostamente neutro e desinteressado, ou estritamente "técnico", esteja não apenas perdendo a oportunidade de contribuir para os debates que envolvem educação, cultura e sociedade, mas, em última instância, contribuindo para processos de exclusão social. (LUEDY, 2006, p. 106)
\end{abstract}

Embora o autor aponte para a ausência da educação musical nos debates que versam sobre educação, cultura e sociedade, a diversidade cultural tem sido a mais recorrente na literatura, especialmente nas revistas e anais da 
ABEM. Para Souza (2007, p.15), a "educação musical, como uma área que se comunica com as chamadas ciências sociais (Kraemer, 2000), a vinculação entre cultura e diversidade entra na pauta de debates, principalmente daqueles relacionados à criação de políticas públicas para o ensino de música". É essa relação entre cultura e diversidade, então, outra perspectiva abordada pelos autores brasileiros.

A aproximação com outras áreas do conhecimento e subáreas da música, como a "etnomusicologia, antropologia cultural e educação em geral" (QUEIROZ, 2004, p. 99), conduziu a pesquisa de alguns investigadores da área. Em pesquisa bibliográfica, Queiroz (2004, p. 100) buscou "compreender de forma mais específica dimensões epistemológicas para a educação musical brasileira na contemporaneidade, a partir de suas relações com a cultura desse país e com a música de outros contextos culturais mais amplos". Disso, resultaria, segundo o autor, inúmeras contribuições para o processo educacional. Dentre elas:

- experiências educativas que interajam com a realidade de cada cultura;

- ensino contextualizado com os diferentes universos musicais da vida cotidiana;

- práticas e vivências musicais que retratem experiências significativas para cada sujeito do processo educativo;

- visão mais ampla dos valores culturais/musicais da sociedade;

- vivências musicais distintas que permitam ao indivíduo de um determinado contexto conhecer e reconhecer diferentes "sotaques" culturais, inclusive o seu próprio;

- ampliação estética e artístico-musical a partir do conhecimento e da experiência com diferentes aspectos de distintas culturas;

- valorização e aproveitamento do aprendizado musical proporcionado pelos diferentes meios e agentes presentes no processo musical de cada cultura (QUEIROZ, 2004, p. 105).

Numa outra direção, Arroyo (2000) explica assim suas decisões em relação à investigação realizada em dois contextos culturais distintos de Uberlândia - MG, a Festa do Congado e o Conservatório de Música: "sendo a cultura - ou, mais especificamente, a diversidade cultural - o objeto de estudo da Antropologia, propus lançar um olhar antropológico sobre práticas de educação musical" (ARROYO, 2000, p. 14). Nessa perspectiva, a autora concluiu que

as práticas de educação musical, escolares ou não-escolares, são espaços de criação e recriação de significados e, portanto, de cultura. Nesse sentido, educação musical deve ser muito mais do que aquisição de competência técnica; ela deve ser considerada como prática 
cultural que cria e recria significados, que conferem sentido à realidade. (ARROYO, 2000, p. 19)

Em suas considerações, a autora afirma que o desafio "mais premente é a formação inicial e continuada de educadores musicais" (ARROYO, 2000, p. 19). Para isso, são necessários "currículos menos tecnicistas e mais socioculturalmente sustentados" (2000, p.19).

O currículo é o foco de Oliveira (2006, p. 30), e sua "contribuição para formar profissionais que visam articulações pedagógicas e musicais na diversidade sociocultural" se apresente sob a forma de uma abordagem pedagógica. A essa abordagem, a autora denomina Pontes - atitude positiva (Positividade), observação, naturalidade, técnica, expressividade e sensibilidade - e a considera como "um guia para o ensino e para a ação em educação musical" (OLIVEIRA, 2006, p. 30). Os currículos de licenciatura em música deveriam, segundo a autora, "preparar os nossos futuros professores com uma base filosófica, pedagógica, musical e multidisciplinar, articuladora e investigativa" (OLIVEIRA, 2006, p. 27). Além disso,

\begin{abstract}
Precisam também desenvolver competências para lidar com a diversidade social e artística que se apresenta nos vários contextos, com uma visão clara do que a educação musical pretende desenvolver, enfatizando não somente os processos educativos, mas também mostrando resultados nos vários setores da cadeia produtiva, em especial na de formação musical. (OLIVEIRA, 2006, p. 27)
\end{abstract}

Já é possível perceber em alguns cursos de licenciatura em música o intuito de "proporcionar [ao estudante a capacidade] de lidar com a multiculturalidade oriunda das diferenças culturais de cada sociedade e dos distintos contextos de ensino e aprendizagem da música" (QUEIROZ; MARI$\mathrm{NHO}, 2005$, p. 86). No entanto, Penna (2005, p. 15) nos adverte que, na formação de professores para uma sociedade multicultural, "mesmo os educadores que discutem o multiculturalismo como proposta orientadora dos currículos reconhecem a sua dificuldade em chegar à sala de aula, a dificuldade de as propostas e concepções se traduzirem no currículo em ação".

Essas dificuldades estariam relacionadas com o fato de "o multiculturalismo aponta[r] para a educação musical [...] a necessidade de trabalhar com a diversidade de manifestações artísticas, considerando a todas como significativas, inclusive conforme sua contextualização em determinado grupo cultural" (PENNA, 2006, p. 39). Por isso,

Esta necessidade de o educador compreender, respeitar e interagir com a especificidade do grupo implica uma postura de aceitação da diversidade - e queremos 
enfocar, particularmente, a diversidade cultural. Lidar com a pluralidade evita, portanto, o etnocentrismo de tomar como referência a nossa própria música (inclusive considerando-a "redentora"), desconsiderando as produções artísticas, culturais e musicais dos grupos com que se trabalha. (PENNA, 2006, p. 38-39)

Além disso, é necessário, segundo Kleber (2006, p. 93), adotar-se "uma perspectiva integradora de educação musical e que abarque a diversidade cultural inerente ao processo pedagógico". A autora acrescenta às questões já citadas aquelas que considera "prementes e problemáticas presentes em nossa sociedade como exclusão e desigualdade social, violência urbana e falta de políticas públicas explícitas para apontar horizontes positivos" (KLEBER, 2006, p. 93).

Alguns trabalhos desenvolvidos sobre a diversidade cultural trazem a questão racial como elemento contextualizador. A diversidade étnico-racial, especialmente a ligada aos afro-brasileiros, permeia as investigações de Conde e Neves (1984), Prass (1998), Tanaka (2001), Candusso (2002), Fialho (2003) e Araldi (2004), entre outros. No entanto, as aproximações teóricas com a etnomusicologia são perceptíveis nos quatro primeiros trabalhos citados, enquanto nos outros dois, o viés é sociológico. Em nenhum deles, o objetivo era estabelecer a relação entre diversidade e formação de professores.

Além desse enfoque, o termo diversidade também é discutido sob a perspectiva geracional (FERNANDES, 2005; RIBAS, 2006). Ribas (2006, p. 132) afirma que, na Educação de Jovens e Adultos (EJA), "a cultura escolar [...] está baseada em um modelo institucional cuja organização foge ao que se considera a regra nas escolas de ensino básico, ou seja, em vez de organizar turmas separando estudantes por faixas de idade, é a diversidade etária que a constitui." Fernandes (2005), por sua vez, em pesquisa sobre a EJA, no município do Rio de Janeiro, propõe aos pesquisadores

explorar mais o campo da educação de adultos, para dar suporte aos educadores musicais no que toca ao processo de aprendizagem da música durante o percurso de vida humano, incluindo a idade adulta e a velhice, e não somente a infância. (FERNANDES, 2005, p. 38)

O suporte aos educadores musicais, sugerido pelo autor, pode começar já em sua formação. Santos (2005, p. 50), em sua reflexão sobre políticas de formação, adverte para a articulação do espaço acadêmico e outros "círculos de sociabilidade e formação". Ressalta, ainda, que, "onde antes reinavam os discursos normativos sobre como se ensina, hoje nos damos conta de uma diversidade de modos de aprender e de ensinar, de contextos e práticas musicais, de funções da música e concepções de músico" (SANTOS, 2005, p. 50). 


\section{Cristiane Almeida}

Essa abordagem é semelhante a de Ribeiro (2008) que introduz os estudos intermulticulturais como perspectiva teórica para refletir sobre a formação de professores de música. Essa temática "tem assumido um espaço importante no âmbito do seu significado não apenas pedagógico, mas social, cultural e político dentro das discussões da área de educação musical" (RIBEIRO, 2008, p. 130). Por isso, dentre as suas indicações, estão as questões culturais, que "precisam ser consideradas como importante na formação de professores [pois] representam elementos para se mudar a prática pedagógica que se quer mais crítica" (RIBEIRO, 2008, p. 133). Essa autora apresenta, assim, a formação de professores de música como "um exercício contínuo, dinâmico e desafiador. [E] um dos desafios maiores continua sendo o de formar para a diversidade, para 0 multicultural, para a complexidade" (RIBEIRO, 2008, p.135).

Ainda sob essa perspectiva, Almeida (2010, p. 51) aponta a formação de professores de música como "um espaço de inter-relações, onde os diálogos interculturais sejam exercitados e, consequentemente, seja possível viver a formação com/em a diversidade para formar professores de música que possam trabalhar com/em a diversidade". Dessa forma, "temas 'delicados', como religião, orientação sexual, raça, etnia, preconceitos, racismos, [poderão] encontrar lugar e ampliar os conceitos de educação musical multicultural" (ALMEIDA, 2010, p. 51).

\section{Considerações finais}

Não tive a pretensão de esgotar o tema neste artigo, mas iniciar seu mapeamento na legislação educacional e na literatura da área. Dada a polissemia do termo diversidade, muitos outros trabalhos poderiam ser incluídos. No entanto, considerei que os trabalhos aqui apresentados foram suficientes para estabelecer o confronto entre a perspectiva dos documentos oficiais e a dos educadores musicais.

Seguindo a linha do tempo, observei que a discussão na área de música, se aproxima, cada vez mais, das categorias explicitadas nos documentos referentes à Educação Básica. A concepção de educação musical multicultural, que priorizava o repertório, foi ampliada, incluindo, assim, outras categorias, tornando-a mais inclusiva. Essa mudança, entretanto, não pode ser só retórica ou ter como finalidade atender à legislação. Deve refletir, principalmente, a postura política dos educadores musicais em participar e contribuir para "uma educação fundada no diálogo entre as diferentes culturas, aberto e democrático" (CAPELO, 2003, p. 129).

\section{Referências}

ALMEIDA, C. M. G. Diversidade e formação de professores de música. Revista da ABEM, Porto Alegre, v. 24, p. 45-53, set. 2010. 
ABRAHAMS, F. Aplicação da pedagogia crítica ao ensino e aprendizagem de música. Revista da ABEM, Porto Alegre, v. 12, p. 65-72, mar. 2005.

ABRIL, C. Learning outcomes of two approaches to multicultural music education. International Journal of Music Education, vol. 24, n. 1, p. 30-42, 2006. Disponível em: <http://ijm.sagepub.com/content/vol24/issue1/>. Acesso em: 26 setembro 2006.

ANDERSON, W. M.; CAMPBELL, P. S. (Eds.). Multicultural perspectives in music education. Reston: MENC, 1996.

ARALDI, J. Formação e prática musical de DJs: um estudo multicaso em Porto Alegre. 2004. Dissertação (Mestrado em Música) - Instituto de Artes, Universidade Federal do Rio Grande do Sul, Porto Alegre.

ARROYO, M. Um olhar antropológico sobre práticas de ensino e aprendizagem musical. Revista da ABEM, Porto Alegre, v. 5, p. 13-20, set. 2000.

BOWMAN, W. Re-Tooling "Foundations" to Address 21st Century Realities: Music Education Amidst Diversity, Plurality, and Change. Action, Criticism, and Theory for Music Education, v. 2, n. 2, dec. 2003. Disponível em: <http://mas.siue.edu/ ACT/v2/Bowman03.pdf>. Acesso em: 04 out. 2006.

BRASIL. Lei n. 9.394 de 20 de dezembro de 1996. Estabelece as diretrizes e bases da educação nacional. Disponível em: <http://www.mec.gov.br>. Acesso em: 18 maio 2006.

Secretaria de Educação Fundamental. Parâmetros curriculares nacionais: arte. Brasília: MEC /SEF, 1998.

Parecer CNE/CP n. 9/2001. Diretrizes Curriculares para a Formação de Professores da Educação Básica, em nível superior, curso de licenciatura, de graduação plena. Brasília, 2001. Disponível em: <http:// www.mec.gov.br>. Acesso em: 18 jun. 2003.

Resolução CNE/CP n. 1/2002. Diretrizes Curriculares para a Formação de Professores da Educação Básica, em nível superior, curso de licenciatura, de graduação plena. Brasília, 2002. Disponível em: <http:// www.mec.gov.br>. Acesso em: 18 jun. 2003.

Diretrizes Curriculares Nacionais para a Educação das Relações Étnico-Raciais e para o Ensino de História e Cultura Afro-Brasileira e Africana. Brasília: MEC/SEPPIR, jul. 2004.

BURTON, B. The role of multicultural music education in a multicultural society. In: RIDEOUT, R. (Ed.). On the sociology of music education. Oklahoma: University of Oklahoma, 1997. p. 81-84.

CAMPBELL, P. S.; SCHIPPERS, H. Introduction. Local musics, global issues. In: CAMPBELL, P. S. et al. (Eds.). Cultural diversity in music education: 


\section{Cristiane Almeida}

directions and challenges for the $21^{\text {st }}$ century. Brisbane: Australian Academic Press, 2005. p. v-vii.

CANDUSSO, F. A prática pedagógico-musical da banda Lactomia: um estudo de caso. 2002. Dissertação (Mestrado em Música) - Escola de Música, Universidade Federal da Bahia, Salvador.

CANEN, A.; ARBACHE, A. P.; FRANCO, M. Pesquisando multiculturalismo e educação: o que dizem as dissertações e teses. Educação \& Realidade, v. 26, n. 1, p. 161-181, jan./jun. 2001.

CAPELO, M. R. C. Diversidade sociocultural na escola e a dialética da exclusão/inclusão. In: GUSMÃO, N. M. M. (Org.). Diversidade, cultura e educação: olhares cruzados. São Paulo: Biruta, 2003. p. 107-134.

COLWELL, R. Taking the temperature of critical pedagogy. Visions of research in music education, v. 6 - special edition, jan. 2005, p. 1-15. Disponível em: <http://www-usr.rider.edu/ vrme/>. Acesso em: 02 nov. 2006.

CONDE, C.; NEVES, J. M. Música e educação não-formal. Pesquisa e Música, vol. 1, n. 1, p. 41-52, 1984/1985.

ELLIOTT, D. J. Key concepts in multicultural music education. International Journal Music Education, n. 13, p. 11-18, 1989.

EMMANUEL, D. T. The effects of a music education immersion internship in a culturally diverse setting on the beliefs and attitudes of pre-service music teachers. International Journal of Music Education, v. 23, n. 1, p. 49-62, 2005.

FERNANDES, J. N. Educação musical de jovens e adultos na escola regular: políticas, práticas e desafios. Revista da ABEM, Porto Alegre, v. 12, p. 35-41, mar. 2005.

FERREIRA, N. S. A. As pesquisas denominadas "estado da arte". Educação \& Sociedade, a. XXIII, n. 79, ago. 2002, p. 257-272. Disponível em: <http:// www.scielo.br/pdf/es/v23n79/10857.pdf>. Acesso em: 20 ago. 2011.

FIALHO, V. A. M. Hip Hop Sul: um espaço televisivo de formação e atuação musical. 2003. Dissertação (Mestrado em Música) - Instituto de Artes, Universidade Federal do Rio Grande do Sul, Porto Alegre.

GIRALDEZ, A. Educación musical desde uma perspectiva multicultural: diversas aproximaciones. Revista Transcultural de Música/Transcultural Music Review,Translberia 1, nov. 1997. Disponível em: <http://www.sibetrans.com/trans/ transiberia/giraldez.htm>. Acesso em: 27 set. 2005.

GREEN, L. Why 'ideology' is still relevant for critical thinking in music education. Action, Criticism, and Theory for Music Education, v. 2, n. 2, dec. 2003. Disponível em: <http://act.maydaygroup.org/articles/Green2_2.pdf>. Acesso em: 04 out. 2006. 
HENRIQUES, R. et al. Educação escolar indígena: diversidade sociocultural indígena ressignificando a escola. Disponível em: <http://portal.mec.gov.br/secad/ arquivos/pdf/educacaoindigena.pdf>. Acesso em: 02 fev. 2009

Ice.mec.gov.br Disponível em: <http://lce.mec.gov.br/index.php?option=com content\&view=article\&id=109\&ltemid=86>. Acesso em: 07 jul. 2009.

IKEHARA, A. The effect of an introduction to Okinawan music on students' attitudinal statements regarding multicultural music education and people from others cultures. Missouri journal of research in music education, v. 38, p. 30-44, 2001.

JORDAN, J. Multicultural Music Education in a Pluralistic Society. In: COLWELL, R. (Ed.). Handbook of Research on Music Teaching and Learning. Virginia: Music Educators National Conference, 1992. p. 735-748.

KLEBER, M. Educação musical: novas ou outras abordagens - novos ou outros protagonistas. Revista da ABEM, Porto Alegre, v. 14, p. 91-98, mar. 2006.

KRAEMER, R.-D. Dimensões e funções do conhecimento pedagógico-musical. Em Pauta, Porto Alegre, v. 11, n. 16/17, p. 50-73, abr./nov. 2000.

KWAMI, R. Music education in and for a multicultural society. In: PLUMMERIDGE, C. (Ed.). Music education: trends and issues. London: Institute of Education/ University of London, 1996. p. 59-76.

LAZZARIN, L. F. A dimensão multicultural da nova filosofia da educação musical. Revista da ABEM, Porto Alegre, v. 14, p. 125-131, mar. 2006.

Multiculturalismo e multiculturalidade: recorrências discursivas na educação musical. Revista da ABEM, Porto Alegre, v. 19, p. 121-128, mar. 2008.

LOURO, A. L.; ARÓSTEGUI, J. L. Docentes universitários/professores de instrumento: suas concepções sobre educação e música. Em Pauta, Porto Alegre, v. 14, n. 22, p. 35-64, jun. 2003.

LUCAS, M. E. Etnomusicologia e Educação Musical: perspectivas de colaboração na pesquisa. NEA, ano III, n. 1, p. 9-15, abr. 1995.

LUEDY, E. Batalhas culturais: educação musical, conhecimento curricular e cultura popular na perspectiva das teorias críticas em educação. Revista da ABEM, Porto Alegre, v. 15, p. 101-107, set. 2006.

O'FLYNN, J. Re-appraising ideas of musicality in intercultural contexts of music education. International Journal of Music Education, v. 23, n. 1, p. 191-203, dec. 2005.

OLIVEIRA, A. Educação musical e diversidade: pontes de articulação. Revista da ABEM, Porto Alegre, v. 14, p. 25-33, mar. 2006.

A. Ações em formação musical no Brasil e reflexões sobre as relações com a cultura. Revista da ABEM, Porto Alegre, v. 18, p. 53-63, out. 2007. 


\section{Cristiane Almeida}

PENNA, M. Desafios para a educação musical: ultrapassar oposições e promover o diálogo. Revista da ABEM, Porto Alegre, v. 14, p. 35-43, mar. 2006.

PENNA, M. Poéticas musicais e práticas sociais: reflexões sobre a educação musical diante da diversidade. Revista da ABEM, Porto Alegre, v. 13, p. 7-16, set. 2005.

PRASS, L. Saberes musicais em uma bateria de escola de samba: uma etnografia entre os "Bambas da Orgia". 1998. Dissertação (Mestrado em Música) - Instituto de Artes, Universidade Federal do Rio Grande do Sul, Porto Alegre.

QUEIROZ, L. R. S. Educação musical e cultura: singularidade e pluralidade cultural no ensino e aprendizagem da música. Revista da ABEM, Porto Alegre, v. 10, p. 99-107, mar. 2004.

QUEIROZ, L. R. S.; MARINHO, V. M. Novas perspectivas para a formação de professores de música: reflexões acerca do Projeto Político Pedagógico da Licenciatura em Música da Universidade Federal da Paraíba. Revista da ABEM, Porto Alegre, v. 13, p. 83-92, set. 2005.

RIBAS, M. G. C. Música na educação de jovens e adultos: um estudo sobre práticas musicais entre gerações. 2006. Tese (Doutorado em Música) - Instituto de Artes, Universidade Federal do Rio Grande do Sul, Porto Alegre.

RIBEIRO, S. T. S. O rap e a aula: tocando nas diferenças. Revista da ABEM, v. 19, mar. 2008, p. 129-135.

SANTOS, R. M. S. Música, a realidade nas escolas e políticas de formação. Revista da ABEM, Porto Alegre, v. 12, p. 49-56, mar. 2005.

SCHIPPERS, H. Taking distance and getting up close: the seven-continuum transmission model (SCTM). In: CAMPBELL, P. S. et al. (Eds.). Cultural diversity in music education: directions and challenges for the $21^{\text {st }}$ century. Brisbane: Australian Academic Press, 2005. p. 29-34.

SOUZA, J. Cultura e diversidade na América Latina: o lugar da educação musical. Revista da ABEM, Porto Alegre, v. 18, p. 15-20, out. 2007.

SWANWICK, K. Music education in a pluralist society. International Journal of Music Education, n. 12, p. 3-8, nov. 1988.

TANAKA, $\mathrm{H}$. Ensino e aprendizagem do Cavalo-marinho infantil do bairro dos Novais. In: ENCONTRO ANUAL DAASSOCIAÇÃO BRASILEIRA DE EDUCAÇÃO MUSICAL, 10, 2001, Uberlândia. Anais... Uberlândia: 2001, p. 106-114.

TRAVASSOS, E. Etnomusicologia, educação musical e o desafio do relativismo estético. In: ENCONTRO ANUAL DA ASSOCIAÇÃO BRASILEIRA DE EDUCAÇÃO MUSICAL, 10, 2001, Uberlândia. Anais... Uberlândia: 2001, p. 75-84. 
VOLK, T. M. The history and development of multicultural music education as evidence in the Music Educators Journal, 1967-1992. Journal of Research in Music Education, Columbia, v. 41. n. 2, p. 137-155, sum. 1993.

\section{Correspondência}

Cristiane Almeida - Rua Rua Agricolândia, 150/104, Várzea, 50740-470 - Recife - Pernambuco. E-mail: cmgabr@yahoo.com.br

Recebido em 20 de outubro de 2011

Aprovado em 27 de novembro de 2011 